\title{
Foreign ant queens are accepted but produce fewer offspring
}

\author{
Barbara Holzer $\cdot$ Michel Chapuisat $\cdot$ Laurent Keller
}

Received: 9 April 2008 / Accepted: 9 June 2008 / Published online: 12 July 2008

(C) Springer-Verlag 2008

\begin{abstract}
Understanding social evolution requires us to understand the processes regulating the number of breeders within social groups and how they partition reproduction. Queens in polygynous (multiple queens per colony) ants often seek adoption in established colonies instead of founding a new colony independently. This mode of dispersal leads to potential conflicts, as kin selection theory predicts that resident workers should favour nestmate queens over foreign queens. Here we compared the survival of foreign and resident queens as well as their relative reproductive share. We used the ant Formica exsecta to construct colonies consisting of one queen with workers related to this resident queen and introduced a foreign queen. We found that the survival of foreign queens did not differ from that of resident queens over a period of 136 days. However, the genetic analyses revealed that resident queens produced a 1.5-fold higher number of offspring than introduced queens, and had an equal or higher share in $80 \%$ of the colonies. These data indicate that some discrimination can occur against dispersing individuals and that dispersal can thus have costs in terms of direct reproduction for dispersing queens.
\end{abstract}

Keywords Queen acceptance - Reproductive skew · Dispersal $\cdot$ Social insects $\cdot$ Ants

Communicated by Roland Brandl.

B. Holzer $\cdot$ M. Chapuisat $\cdot$ L. Keller $(\bowtie)$ Department of Ecology and Evolution,

University of Lausanne, Biophore,

1015, Lausanne, Switzerland

e-mail: Laurent.Keller@unil.ch

B. Holzer

e-mail: barbara.holzer@unil.ch

\section{Introduction}

One of the major transitions in evolution is the shift from solitary organisms to societies with reproductive division of labour (Maynard Smith and Szathmary 1995; Szathmary and Maynard Smith 1995). Understanding social evolution requires us to understand the processes regulating the number of breeders within social groups and how they partition reproduction (Bourke and Franks 1995; Keller and Chapuisat 1999; Reeve and Keller 2001). In ants and termites, as well as some bees and wasps, reproduction is almost exclusively monopolised by queens, while workers undertake non-reproductive tasks such as foraging. In these social insects, colonies may frequently contain two or more fertile queens (polygynous) and workers interact with nestmates of varying degrees of relatedness. According to kin selection theory, workers may thus increase their inclusive fitness by preferentially caring for the brood of their mother (Hamilton 1987).

Behavioural and genetic studies revealed that there is considerable intra- and interspecific variation in the relative reproductive success of queens (Keller 1993a, 1995; Bourke and Franks 1995). These differences can arise from several factors, including variation amongst queens in their fecundity (Keller 1988; Vásquez and Silverman 2008), the proportion of their eggs developing to adulthood (Hannonen and Sundström 2003b; Holzer et al. 2006), and the likelihood of eggs developing into workers, young queens, or males (Ross 1988, 1993; Keller 1993b; Pamilo and Seppä 1994; Bourke et al. 1997; Fournier and Keller 2001; Heinze et al. 2001; Rüppell et al. 2002; Fournier et al. 2004; Hammond et al. 2006; Kümmerli and Keller 2007b).

As in most animal societies, another key aspect of polygynous colonies is that within a colony individuals are not all 
equally related. For example, in many species some queens remain in, or return to, their parental colony after mating, while others disperse to foreign colonies (Rosengren and Pamilo 1983; Bourke and Franks 1995). These differences in dispersal strategies translate into workers being more related to resident than dispersing queens. Accordingly, workers may increase their inclusive fitness by preferentially recruiting queens from within their colony and favouring the reproduction of the more closely related resident queens over the less related foreign queens (Nonacs 1988; Crozier and Pamilo 1996).

Several studies have investigated whether colonies are more likely to accept queens originating from the same colony compared to foreign queens. In Formica exsecta newly emerged virgin queens were more likely to be accepted in female-producing colonies, and were mostly killed in colonies that produced only males (Brown et al. 2003). A study of Formica truncorum suggests that the mating status of queens influences their acceptance. Specifically, workers in laboratory colonies did not distinguish between nestmate and non-nestmate queens, but were more likely to accept virgin than mated queens (Sundström 1997). In Formica paralugubris, introductions of queens in female-producing nests showed that virgin queens were accepted with a higher probability than mated queens, and suggested that the survival of introduced queens did not differ between natal and foreign nests (Fortelius et al. 1993). In Formica polyctena, all old foreign and mated queens were accepted (Rosengren et al. 1986). A recent laboratory study of the ponerine ant Pachycondyla luteipes showed that mated and reproductive active queens were accepted in their nest of origin, whereas $70 \%$ of the non-nestmate queens were rejected (Kikuchi et al. 2007). Similarly, in the Argentine ant Linephitema humile nestmate queens were generally accepted (90\%), but most of the queens introduced into foreign colonies were killed (Vásquez and Silverman 2008). Finally, in Leptothorax curvispinosus all foreign queens were rejected (Stuart et al. 1993), and in Myrmica tahoensis the acceptance rate of old queens was about 23\% (Evans 1996).

The degree of reproductive skew and partitioning of reproduction amongst queens has also been investigated in several ant species. For example, $F$. exsecta queens were shown to differ in their relative contribution to gynes, males and workers (Kümmerli and Keller 2007b), while the relative contribution of queens to the brood was unequal in $50 \%$ of the colonies in Formica fusca (Hannonen and Sundström 2003a). Many other studies also reported different degrees of reproductive skew for the production of sexuals and/or workers (Ross 1988, 1993; Pamilo and Seppä 1994; Bourke et al. 1997; Fournier and Keller 2001; Rüppell et al. 2002; Fournier et al. 2004; Langer et al. 2004; Hammond et al. 2006), yet almost no information is available on whether differences amongst queens in their relatedness to other colony members affects their share in reproduction. The only information on this is for the ant $F$. fusca, where the reproductive share of queens more closely related to workers was shown to increase during brood development (Hannonen and Sundström 2003b). However, this pattern can be explained either by nepotism, with workers preferentially rearing the brood of more closely related queens, or intrinsic differences in the viability of eggs laid by queens (Holzer et al. 2006).

The aim of this study was twofold. First, we tested whether colonies accept foreign queens of similar age as the resident queen. Second, we compared the number of offspring produced by the resident and introduced queens. To conduct these experiments we selected a polygynous population of the ant $F$. exsecta. In this species young queens can participate in a mating flight and found a new colony independently by parasitizing other Formica species, participate in the mating flight and seek adoption in a foreign established colony, or stay and mate within their nest (Kutter 1969). Several lines of evidence indicate that queens can successfully enter foreign colonies. First, a genetic study in the field revealed that queen number can increase in colonies producing only males and workers during several years despite the fact that these colonies reject almost all young queens that seek adoption in their nest during the period of mating flight (Brown et al. 2003; Kümmerli and Keller 2008). Second, experiments showed that field colonies readily accept adult queens during the whole summer and that these queens can contribute to brood production (Brown and Keller 2002; Kümmerli et al. 2005). Finally, we also observed movement of marked workers between field colonies (up to several hundred metres in some cases), raising the possibility that dispersing on foot may also be a route of natural movement of queens between established colonies (Kümmerli and Keller 2007a).

To estimate the rate of queen acceptance into foreign established colonies, and to quantify the reproductive share of resident and introduced queens, we created single queen colonies that were kept for 1 year in the laboratory and then introduced a foreign queens originating from another colony kept under similar conditions. To our knowledge, this is the first study that quantifies survival of foreign queens over a long period (136 days) and experimentally compares the contribution of resident and foreign queens to brood production.

\section{Materials and methods}

Field collection and experimental set up

We collected $F$. exsecta ants from a polygynous population at La Dunanche $\left(46^{\circ} 28^{\prime} \mathrm{N}, 6^{\circ} 11^{\prime} \mathrm{E}\right)$ in the Swiss Jura mountains 
between 21 and 25 April 2004. From each of 104 colonies we established one colony in the laboratory with one adult queen and approximately 500 workers. These colonies were kept at $22-24^{\circ} \mathrm{C}$ in nests $(26 \mathrm{~cm} \times 41 \mathrm{~cm} \times 15 \mathrm{~cm})$ containing peat as nest material and a tile as nesting site. During the winter period of 2004/2005 colonies were kept for 4 months at $5^{\circ} \mathrm{C}$. Ants were regularly fed with honey water and a mixture of agar, egg, honey and water.

In March 2005 after over-wintering, the colonies were checked daily to determine when queens resumed egg production. As soon as eggs were found, we colour-marked the queen and transferred her with approximately 300 workers but no brood to a new nest. The next day we randomly assigned pairs of newly formed colonies as donor or recipient colonies and transferred the queen from the donor colony to the recipient colony. In total we introduced 38 queens from donor colonies into 38 recipient colonies over a period of 9 days. The resident and introduced queens had similar fecundity as indicated by the lack of a significant difference in the number of brood they produced in the previous year (2004, mean $\pm \mathrm{SD}$, resident queens $226 \pm 75$; introduced queens $203 \pm 52$; paired $t$-test, $t_{24}=1.26$, $P=0.22$ ).

To analyse the reproductive share of each queen, we sampled all the newly reared pupae at week $6,7,9,11,13$, 15,17 , and 19. At week 6, 13, and 19 we also verified if the resident and introduced queens were alive or dead. Because some workers died during the course of the experiments we collected and genotyped in each colony four workers collected at the start and four workers collected at the end of the experiment to obtain an average measure of the relatedness between workers and the resident and introduced queens.

Out of the 38 experimental colonies, 13 produced less than four offspring or one of the queens was found dead during the first sampling. These colonies were excluded from the maternity analyses. The remaining 25 colonies produced on average $( \pm \mathrm{SD}) 121 \pm 95$ pupae with a minimum of 12 and a maximum of 395 pupae.

Genotyping and maternity assignment

To assign the relative contribution of queens, we collected all the pupae produced and genotyped the queens as well as a minimum of 39 pupae per nest, with the exception of the five colonies that produced less than 39 pupae. In the 17 colonies that produced between 65 and 395 pupae, we genotyped $25-65 \%$ of the sampled pupae (pupae were mixed and a subset was chosen randomly). We used four highly polymorphic microsatellite loci: FL21 (Chapuisat 1996), FE13, FE17 and FE37 (Gyllenstrand et al. 2002). DNA was extracted from the head of workers, the head of the pupae, or the entire pupae following the procedure described in Kümmerli et al. (2005) and Holzer et al. (2006). Polymerase chain reaction products were mixed and run on an automatic sequencer (ABI Prism 3100). The number of alleles per locus ranged from six to 19 (mean $\pm \mathrm{SD}, 12.0 \pm 4.6$ ), with an expected heterozygosity between 0.61 and 0.87 .

\section{Statistical analyses}

The Kaplan-Meier procedure was used to test for differences in survival between resident and introduced queens. The relatedness of the eight genotyped workers towards the resident and introduced queens, as well as the relatedness of workers towards the pupae produced by the resident and introduced queen, were calculated with the program Relatedness 5.0.8 (Queller and Goodnight 1989). To test whether the resident queen produced more than $50 \%$ of the offspring, we performed a one-sample $t$-test. We also conducted a $t$-test between the pupae produced in weeks 1-7 and weeks $8-19$ to determine whether there was a change over time in the relative contribution of the introduced queen. In weeks $8-19$, we excluded nine colonies for which less than three offspring were genotyped.

\section{Results}

The survival of introduced and resident queens was similar during the course of the experiment. Out of the 76 queens, nine introduced and ten resident queens died (KaplanMeier, $\log$ rank $=0.04, d f=1, P=0.85$; Fig. 1 ).

The mean relatedness \pm SE between workers and the resident queen was $r=0.38 \pm 0.02$. The relatedness of

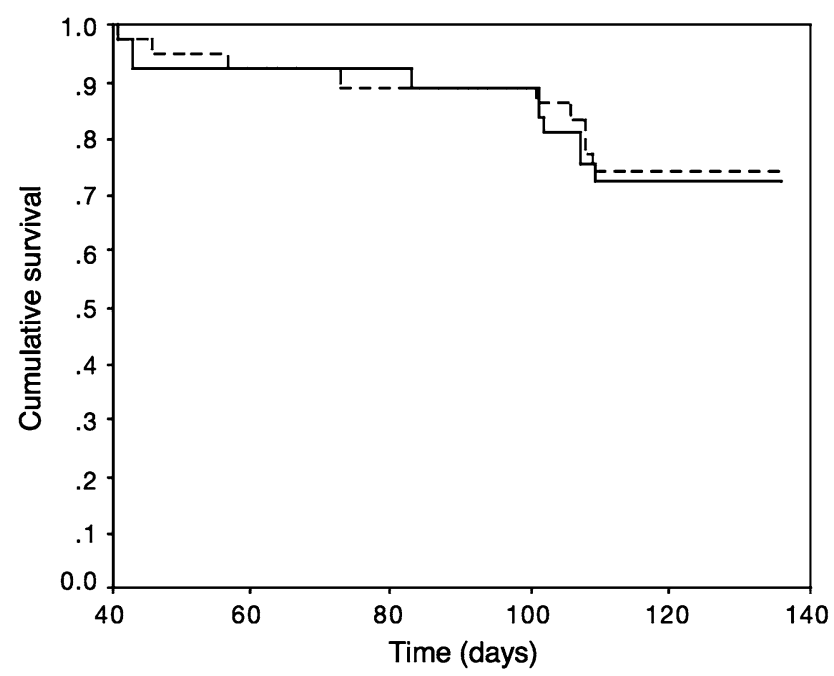

Fig. 1 Colonies of the ant Formica exsecta accept unrelated queens as shown by the similar survival of introduced queens (dashed line) and resident queens (solid line) 
workers toward the resident queen is lower than expected for full sisters $(r=0.75)$, because 48 of the 200 genotyped workers had genotypes incompatible with those expected from the resident queens (i.e. they remained from the field collection) and $34 \%$ of the queens had mated with multiple males (mean mating frequency $=1.3$ ). The relatedness value between workers and the introduced queen was only $r=0.02 \pm 0.03$, which is not significantly different from zero and significantly lower than the relatedness between workers and the resident queen (paired $t$-test, $t_{24}=7.50$, $P<0.001)$. This difference in relatedness between workers and the introduced and resident queens translated into workers being significantly more related to the pupae of the resident queen $(r=0.47 \pm 0.01)$ than pupae produced by the introduced queen $(r=0.02 \pm 0.04$; paired $t$-test, $\left.t_{24}=9.10, P<0.001\right)$.

We successfully assigned maternity of 1,064 pupae to either the resident or introduced queen (mean \pm SE per colony, $43 \pm 4$ ). In $80 \%$ of the colonies the resident queen had an equal (four colonies) or higher (16 colonies) reproductive share than the introduced queen (Fig. 2). The proportion of offspring reared from the resident queen was $0.60 \pm 0.20$ (mean $\pm \mathrm{SD}$ ). This value is significantly greater than 0.5 , the expected value if the resident and introduced queens share reproduction equally (one-sample $t$-test, $t_{24}=2.49, P=0.02$ ). There was no evidence that the relative share of reproduction of the resident queens decreased over time. Their average \pm SD relative share of reproduction was $0.62 \pm 0.24$ in weeks $1-7$ and $0.61 \pm 0.28$ in weeks $8-19\left(t\right.$-test, $\left.t_{39}=0.19, P=0.85\right)$. Thus, overall resident queens had 1.5 -fold higher contribution to offspring production than introduced queens.

A comparison across colonies revealed that there was not a significant correlation between overall colony productivity and degree of skew (Pearson's correlation coefficient, $\left.r_{p}=0.00, n=25, P=1\right)$. The correlation between the relatedness of the workers to the resident queen and the relative brood production of the resident queen was also not significant (Pearson's correlation coefficient, $r_{p}=-0.11, n=25$, $P=0.61)$.

\section{Discussion}

Our introduction experiments reveal that foreign $F$. exsecta queens are readily accepted in established colonies, even when these contain a single queen and mostly workers which are the daughters of this queen. This result is consistent with previous studies showing that queens in $F$. exsecta are rarely rejected (Brown et al. 2003; Kümmerli et al. 2005). So far most studies have only focused on the survival of queens over a few days after introduction (Rosengren et al. 1986; Bennett 1988; Fortelius et al. 1993; Stuart et al. 1993; Evans 1996; Sundström 1997; Brown et al. 2003; Kikuchi et al. 2007; Vásquez and Silverman 2008). This is the first long-term comparison of survival of dispersing and non-dispersing queens in ants.

A surprising result of this study was that while foreign queens were readily accepted in colonies, they contributed less to brood production than the resident queens over the 19 weeks of the experiment. This result cannot be explained by age or differences in condition between resident and introduced queens as they all originated from field colonies collected at the same time. Moreover, all queens were kept under similar conditions and had produced a similar number of brood in the year before the introduction experiment (see "Materials and methods"). Finally, there was no significant change between weeks 1-7 and weeks $8-15$ in the relative contribution of the foreign queens, indicating that their lower contribution to brood production is not a transient phenomenon after their introduction into foreign colonies.

There are two possible explanations for the lower contribution by the introduced queens to brood production. The first is that workers preferentially rear the brood of the more related queen. Such a mechanism had been proposed for the ant $F$. fusca where experiments showed that queens more closely related to the workers increased their reproductive share during brood development (Hannonen and Sundström 2003b). However, in this experiment the pattern might also have arisen from brood viability differences between queens because, everything else being equal, the queen
Fig. 2 The relative contribution of the resident queen to brood production (black bars) and the percentage of pupae genotyped (grey bars) in each of the 25 colonies

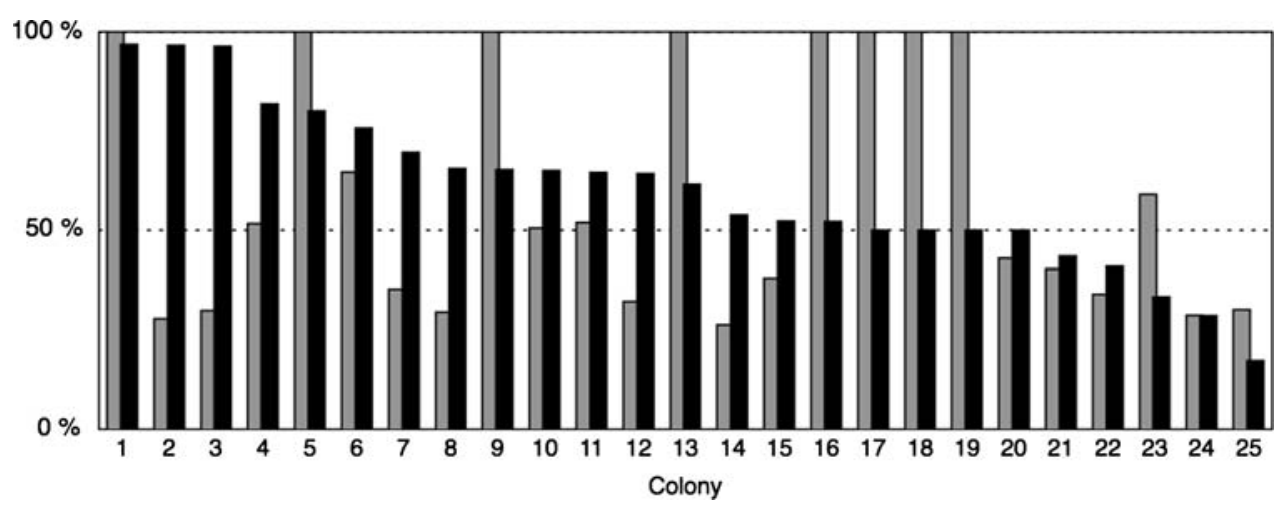


with higher brood viability will produce more offspring and thus be more closely related to the workers (Holzer et al. 2006).

In our study species $F$. exsecta, a cross-fostering experiment indeed revealed differences amongst queens in brood viability, but failed to find evidence that workers discriminated and preferentially reared the brood of the more related queen (Holzer et al. 2006). More generally, numerous other experiments also demonstrated that social insect workers fail to be nepotistic when discrimination can occur only on the basis of an innate recognition of genetically specified cues (Breed et al. 1994; Keller 1997; Queller and Strassmann 2002; Tarpy et al. 2004; Ratnieks et al. 2006). Thus, it seems unlikely that the higher productivity of resident queens in our experiments resulted from workers preferentially rearing their brood compared to that of the introduced queen.

The second explanation is that workers treated the resident and introduced queens differently, hence favouring the fecundity of the resident queens. During our experiments we never observed aggressive interactions between queens, nor between queens and workers. However, it cannot be excluded that there were subtle differences in how workers treated the two queens, for example by providing less food to the introduced queen. In this respect it is important to note that such discrimination does not imply that workers use an innate recognition of genetically specified cues to discriminate between the two types of queens. In ants, workers use odour cues to distinguish nestmates from nonnestmates (Crozier and Pamilo 1996). These cues can be endogenous and have a strong genetic component or can be acquired from the environment (e.g. Crozier and Pamilo 1996; Beye et al. 1998; Liang and Silverman 2000). Whatever the sources of cues, workers have to learn or become habituated to the odour of their colony in order to subsequently discriminate between nestmates and non-nesmates (Crozier and Pamilo 1996; Breed et al. 2004; Ozaki et al. 2005). Thus, because most of the workers developed in the colony with the resident queen they might be accustomed to its specific odour and thus possibly had the option to discriminate against the introduced queen. Alternatively, it is also possible that the introduction into a foreign colony directly affected the behaviour and/or physiology of introduced queens, hence affecting their fecundity or attraction to workers. Although we did not observe behavioural differences between introduced and resident queens, we cannot rule out subtle differences.

Regardless of the mechanism involved, the lower contribution of foreign queens to offspring production has important implications with regard to dispersal strategies. In F. exsecta, as in many other highly polygynous ants, queens can either stay in their parental colony or attempt to enter a foreign colony (Rosengren and Pamilo 1983; Cherix et al. 1991; Keller 1991; Chapuisat et al. 1997). In order to compare these two strategies, previous studies have generally compared the probability of acceptance of queens in their parental colony and foreign colonies (Rosengren et al. 1986; Bennett 1988; Fortelius et al. 1993; Stuart et al. 1993; Evans 1996; Sundström 1997; Brown et al. 2003). However, none of these studies determined the survival of queens over long time periods, nor compared the contribution to brood production of resident and introduced queens. How queen age influences the probability of being accepted in foreign nests, and the expected reproductive share after acceptance, also remain to be investigated.

While our study shows that long-time survival does not differ between resident and introduced queens, it also reveals that the two types of queens may differ in their contribution to brood production. In that respect, it is important to note that our colonies were relatively small and produced only workers (except one that produced one male). It will be of interest to investigate how introduced and resident queens contribute to brood production in larger colonies also producing males and new queens, in particular because recent studies of $F$. exsecta and other ant species revealed that queens differ greatly in their relative contribution to worker and queen progeny, as well as male versus female production (Ross 1988, 1993; Pamilo and Seppä 1994; Bourke et al. 1997; Fournier and Keller 2001; Heinze et al. 2001; Rüppell et al. 2002; Fournier et al. 2004; Hammond et al. 2006; Kümmerli and Keller 2007b).

The findings of this study have also implications for our understanding of the dynamics of group structure of other animal species (Komdeur 2006). While there is increasing data on the relative contribution of individuals to group productivity (e.g. Reeve and Keller 2001; Boomsma and Franks 2006; Ratnieks et al. 2006), there is almost no information on whether resident individuals and those that immigrated from foreign groups differ in their contribution to offspring production. Such data are important for an understanding of group dynamics and within-group conflicts. By revealing that dispersing queens, although being readily accepted in foreign colonies, contributed less to brood production than the resident queens, our work calls for similar studies in other social organisms.

Acknowledgements We thank R. Kümmerli for technical assistance, the editor and three anonymous reviewers for useful comments. This study was supported by several grants from the Swiss National Science Foundation to M. C. and L. K. This research complies with the laws of Switzerland, where the research was performed.

\section{References}

Bennett B (1988) Discrimination of nestmate and non-nestmate sexuals by ants (Hymenoptera: Formicidae). Insect Soc 35:82-91 
Beye M, Neumann P, Chapuisat M, Pamilo P, Moritz RFA (1998) Nestmate recognition and the genetic relatedness of nests in the ant Formica pratensis. Behav Ecol Sociobiol 43:67-72

Boomsma JJ, Franks NR (2006) Social insects: from selfish genes to self organisation and beyond. Trends Ecol Evol 21:303-308

Bourke AFG, Franks NR (1995) Social evolution in ants. Princeton University Press, Princeton

Bourke AFG, Green HAA, Bruford MW (1997) Parentage, reproductive skew and queen turnover in a multiple-queen ant analysed with microsatellites. Proc R Soc Lond B 264:277-283

Breed MD, Welch CK, Cruz R (1994) Kin discrimination within honey-bee (Apis mellifera) colonies: an analysis of the evidence. Behav Processes 33:25-39

Breed MD, Diaz PH, Lucero KD (2004) Olfactory information processing in honeybee, Apis mellifera, nestmate recognition. Anim Behav 68:921-928. doi:10.1016/j.anbehav.2003.10.033

Brown WD, Keller L (2002) Queen recruitment and split sex ratios in polygynous colonies of the ant Formica exsecta. Ecol Lett 5:102109. doi:10.1046/j.1461-0248.2002.00291.x

Brown WD, Liautard C, Keller L (2003) Sex-ratio dependent execution of queens in polygynous colonies of the ant Formica exsecta. Oecologia 134:12-17. doi:10.1007/s00442-002-1072-8

Chapuisat M (1996) Characterization of microsatellite loci in Formica lugubris B and their variability in other ant species. Mol Ecol 5:599-601

Chapuisat M, Goudet J, Keller L (1997) Microsatellites reveal high population viscosity and limited dispersal in the ant Formica paralugubris. Evolution 51:475-482

Cherix D, et al (1991) Alternative reproductive strategies in Formica lugubris Zett. (Hymenoptera Formicidae). Ethol Ecol Evol:61-66

Crozier RH, Pamilo P (1996) Evolution of social insect colonies: sex allocation and kin selection. Oxford University Press, Oxford

Evans JD (1996) Queen longevity, queen adoption, and posthumous indirect fitness in the facultatively polygynous ant Myrmica tahoensis. Behav Ecol Sociobiol 39:275-284

Fortelius W, Rosengren R, Cherix D, Chautems D (1993) Queen recruitment in a highly polygynous supercolony of Formica lugubris (Hymenoptera, Formicidae). Oikos 67:193-200

Fournier D, Keller L (2001) Partitioning of reproduction among queens in the Argentine ant, Linepithema humile. Anim Behav 62:1039-1045. doi:10.1006/anbe.2001.1848

Fournier D, Aron S, Keller L (2004) Significant reproductive skew in the facultatively polygynous ant Pheidole pallidula. Mol Ecol 13:203-210. doi:10.1046/j.1365-294X.2003.02036.x

Gyllenstrand N, Gertsch PJ, Pamilo P (2002) Polymorphic microsatellite DNA markers in the ant Formica exsecta. Mol Ecol Notes 2:67-69. doi:10.1046/j.1471-8286.2002.00152.x

Hamilton WD (1987) Discriminating nepotism: expectable, common, overlooked. In: Fletcher DJC, Michener CD (eds) Kin recognition in animals. Wiley, New York, pp 417-437

Hammond RL, Bruford MW, Bourke AFG (2006) A test of reproductive skew models in a field population of a multiple-queen ant. Behav Ecol Sociobiol 61:265-275. doi:10.1007/s00265-0060257-2

Hannonen M, Sundström L (2003a) Reproductive sharing among queens in the ant Formica fusca. Behav Ecol 14:870-875. doi:10.1093/beheco/arg069

Hannonen M, Sundström L (2003b) Worker nepotism among polygynous ants. Nature 421:910. doi:10.1038/421910a

Heinze J, Trunzer B, Holldobler B, Delabie JHC (2001) Reproductive skew and queen relatedness in an ant with primary polygyny. Insect Soc 48:149-153. doi:10.1007/PL00001758

Holzer B, Kümmerli R, Keller L, Chapuisat M (2006) Sham nepotism as a result of intrinsic differences in brood viability in ants. Proc R Soc Lond B 273:2049-2052. doi:10.1098/rspb.2006.3553
Keller L (1988) Evolutionary implications of polygyny in the Argentine ant, Iridomyrmex humilis (Mayr) (Hymenoptera: Formicidae): an experimental study. Anim Behav 36:159-165

Keller L (1991) Queen Number, mode of colony founding, and queen reproductive success in ants (Hymenoptera, Formicidae). Ethol Ecol Evol 3:307-316

Keller L (1993a) Queen number and sociality in insects. Oxford University Press, Oxford

Keller L (1993b) The assessment of reproductive success of queens in ants and other social insects. Oikos 67:177-180

Keller L (1995) Social life: the paradox of multiple-queen colonies. Trends Ecol Evol 10:355-360

Keller L (1997) Indiscriminate altruism: unduly nice parents and siblings. Trends Ecol Evol 12:99-103

Keller L, Chapuisat M (1999) Cooperation among selfish individuals in insect societies. Bioscience 49:899-909

Kikuchi T, Tsuji K, Ohnishi H, Le Breton J (2007) Caste-biased acceptance of non-nestmates in a polygynous ponerine ant. Anim Behav 73:559-565. doi:10.1016/j.anbehav.2006.04.015

Komdeur J (2006) Variation in individual investment strategies among social animals. Ethology 112:729-747

Kümmerli R, Keller L (2007a) Contrasting population genetic structure for workers and queens in the putatively unicolonial ant Formica exsecta. Mol Ecol 16:4493-4503

Kümmerli R, Keller L (2007b) Reproductive specialization in multiple-queen colonies of the ant Formica exsecta. Behav Ecol 18:375-383. doi:10.1093/beheco/ar1088

Kümmerli R, Keller L (2008) Reproductive parameters vary with social and ecological factors in the polygynous ant Formica exsecta. Oikos 117:580-590. doi:10.1111/j.2007.0030-1299.16207.x

Kümmerli R, Helms KR, Keller L (2005) Experimental manipulation of queen number affects colony sex ratio investment in the highly polygynous ant Formica exsecta. Proc R Soc Lond B 272:17891794. doi:10.1098/rspb.2005.3163

Kutter H (1969) Die sozialparasitischen Ameisen der Schweiz. Neujahrsblatt Naturforsch Ges Zürich 5-62

Langer P, Hogendoorn K, Keller L (2004) Tug-of-war over reproduction in a social bee. Nature 428:844-847. doi:10.1038/ nature 02431

Liang D, Silverman J (2000) "You are what you eat": diet modifies cuticular hydrocarbons and nestmate recognition in the Argentine ant, Linepithema humile. Naturwissenschaften 87:412-416. doi:10.1007/s001140050752

Maynard Smith J, Szathmary E (1995) The major transitions in evolution. Freeman, Oxford

Nonacs P (1988) Queen number in colonies of social Hymenoptera as a kin-selected adaptation. Evolution 42:566-580

Ozaki M et al (2005) Ant nestmate and non-nestmate discrimination by a chemosensory sensillum. Science 309:311-314

Pamilo P, Seppä P (1994) Reproductive competition and conflicts in colonies of the ant Formica sanguinea. Anim Behav 48:12011206

Queller DC, Goodnight KF (1989) Estimating relatedness using genetic markers. Evolution 43:258-275

Queller DC, Strassmann JE (2002) The many selves of social insects. Science 296:311-313. doi:10.1126/science.1070671

Ratnieks FLW, Foster KR, Wenseleers T (2006) Conflict resolution in insect societies. Annu Rev Entomol 51:581-608. doi:10.1146/annurev.ento.51.110104.151003

Reeve HK, Keller L (2001) Test of reproductive skew models in social insects. Annu Rev Entomol 46:347-385. doi:10.1007/s00265006-0257-2

Rosengren R, Cherix D, Pamilo P (1986) Insular ecology of the red wood ant Formica truncorum. II. Distribution, reproductive strategy and competition. Mitt Schweiz Entomol Ges 59:63-93 
Rosengren R, Pamilo P (1983) The evolution of polygyny and polydomy in mound-building Formica ants. Acta Entomol Fenn 42:6577

Ross KG (1988) Differential reproduction in multiple-queen colonies of the fire ant Solenopsis invicta (Hymenoptera: Formicidae). Behav Ecol Sociobiol 23:341-355

Ross KG (1993) The breeding system of the fire ant Solenopsis invicta, and its effects on colony genetic structure. Am Nat 141:554-576

Rüppell O, Heinze J, Hölldobler B (2002) Intracolonial patterns of reproduction in the queen-size dimorphic ant Leptothorax rugatulus. Behav Ecol 13:239-247

Stuart R, Gresham-Bisset L, Alloway T (1993) Queen adoption in the polygynous and polydomous ant, Leptothorax curvispinosus. Behav Ecol 4:276-281
Sundström L (1997) Queen acceptance and nestmate recognition in monogyne and polygyne colonies of the ant Formica truncorum. Anim Behav 53:499-510

Szathmary E, Maynard Smith JM (1995) The major evolutionary transitions. Nature 374:227-232. doi:10.1038/374227a0

Tarpy DR, Gilley DC, Seeley TD (2004) Levels of selection in a social insect: a review of conflict and cooperation during honey bee (Apis mellifera) queen replacement. Behav Ecol Sociobiol 55:513-523. doi:10.1007/s00265-003-0738-5

Vásquez G, Silverman J (2008) Queen acceptance and the complexity of nestmate discrimination in the Argentine ant. Behav Ecol Sociobiol 62:537-548. doi:10.1007/s00265-007-0478-z 